\title{
Improved Survival With Higher Pre-diagnosis Cardiorespiratory Fitness in Men Who Developed Digestive System Cancers: A Prospective Pilot Study
}

\author{
BARUCH VAINSHELBOIM ${ }^{1}$, ZHONGMING CHEN $^{1,2}$ and JONATHAN MYERS \\ ${ }^{1}$ Cardiology Division, Veterans Affairs Palo Alto Health Care System/ Stanford University, Palo Alto, CA, U.S.A.; \\ ${ }^{2}$ School of Medicine, New York Medical College, Valhalla, NY, U.S.A.
}

\begin{abstract}
Background/Aim: Digestive system cancers are the leading cause of cancer mortality and have poor survival particularly in men. The study aimed to assess the association between pre-diagnosis cardiorespiratory fitness (CRF) and cancer mortality in a pilot sample of men who developed digestive system cancers. Patients and Methods: Pre-diagnosis CRF (treadmill exercise test) was assessed in 342 men (68.9 \pm 21.8 years) who developed digestive system cancers during $6.7 \pm 5$ years from baseline evaluation. Cox multivariable hazard models were analyzed for total cancer mortality. Results: During 7.2 \pm 5 years follow-up from baseline, 120 participants died from cancer. Compared to low CRF, moderate and high CRF levels were associated with $57 \%$ [0.43, 95\%CI $=0.24-0.74]$ and $73 \%[0.27,95 \% C I=0.12-0.59]$ reduced risks for cancer mortality, respectively ( $p$ trend $=0.002$ ). Survival time from baseline was longer among those with moderate [13.5 (range $=12.1-14.9$ ) years] and high [16.1 (range $=14.0-18.2$ ) years] compared to low CRF [7.9 (range=5.7-10.1) years]. Conclusion: Higher pre-diagnosis CRF is independently associated with lower risk of cancer mortality and longer survival in men who later developed digestive system cancers.
\end{abstract}

Digestive system cancers as a group are the most common diagnosed cancers and the leading cause of cancer-related deaths worldwide and in US $(1,2)$. Digestive system cancers include esophagus, stomach, small intestine, colon, rectum, anus, anal canal, anorectum, liver, intrahepatic bile duct, gallbladder, pancreas and other digestive organs (1). Globally,

This article is freely accessible online.

Correspondence to: Baruch Vainshelboim, Ph.D., ACSM-RCEP, ACSM/ACS-CET, VA Palo Alto Health Care System, Cardiology 111C, 3801 Miranda Ave, Palo Alto CA 94304, U.S.A. Tel: +1 6504935000 x64661, Fax: +1 6508523473, e-mail: baruch.v1981@ gmail.com

Key Words: Exercise testing, exercise capacity, cancer mortality. approximately 5.3 million digestive system cancers were diagnosed and more than 3.5 million died from these in 2018 (2). The American Cancer Society estimates that 328,030 new cases of digestive system cancers will be diagnosed and 165,460 will die from these in the US during 2019. The 5-year survival rates from digestive system cancers are relatively poor, ranging from $65 \%$ in colon and rectum to $31 \%$ for stomach cancer, $19 \%$ for esophageal cancer, $18 \%$ for liver cancer and $9 \%$ for pancreatic cancer (1).

Efforts to improve survival from digestive system cancers have shown encouraging results particularly using screening and early detection for colorectal cancer, although for other cancers such as esophageal, liver and pancreatic cancer, the survival rates remain poor, and evidence-based screening tools that improve survival are lacking (3). The American Heart Association recently endorsed cardiorespiratory fitness (CRF) as potential screening tool for health outcomes, providing a strong case for using CRF as a vital sign (4). In this regard, low CRF has been established as a risk factor associated with many chronic conditions as well as all-cause, cardiovascular and cancer mortality $(4,5)$. Although higher CRF has been extensively demonstrated to have protective benefits for health outcomes (4), few studies have assessed the association between CRF and incidence of colorectal and gastro-intestinal cancers (6-8). Only one study has reported on the inverse association between CRF and mortality from digestive system cancers among the general population (9).

To our knowledge, the potential survival benefits of higher pre-diagnosis CRF in men who developed digestive system cancers has yet to be explored. Such data would have potentially important public-health implications for cancer prevention and control of digestive system cancers. Therefore, the aim of the current study was to assess the association between pre-diagnosis CRF and cancer mortality in a pilot sample of men who developed digestive system cancers. Additionally, the study aimed to quantify the potential public health implications of CRF in prevention and control of digestive system cancers. 


\section{Patients and Methods}

The present analysis utilized the Veterans Exercise Testing Study (VETS), which has been previously described $(10,11)$. In brief, the VETS cohort is an ongoing, prospective evaluation of primarily male $(96 \%)$ Veterans referred for exercise testing for clinical reasons, and has been designed to address the association of exercise test, clinical, and lifestyle factors with health outcomes. The sample generally included participants with cardiometabolic risk factors, signs or symptoms suggestive of cardiovascular disease, or known cardiometabolic disease. The study was approved by the Institutional Review Board at Stanford University, CA, USA. All participants who underwent a treadmill exercise test at the Veterans Affairs Palo Alto Health Care System between 1987 and 2014 were considered for inclusion. Clinical information on diagnoses, risk factors and health behaviors (smoking, alcohol and drug abuse) were collected at the time of the exercise test using the Veterans Affairs Computerized Patient Record System (CPRS) and selfreported health history. The current study included male participants who were free from any malignancy at baseline and who developed one or more of digestive system cancers (esophagus, stomach, small intestine, colon, rectum, anus, anal canal, anorectum, liver, intrahepatic bile duct, gallbladder, pancreas and other digestive system organs) during $6.7 \pm 5$ years from baseline.

Cardiorespiratory fitness. At baseline, participants underwent maximal symptom-limited exercise testing using an individualized ramp treadmill protocol according to established guidelines $(12,13)$. The exercise protocol included continuous, individualized increments in treadmill speed and grade adjusted to achieve a targeted duration between 8 and 12 minutes as previously recommended $(12,13)$. A 12-lead electrocardiogram, heart rate, blood pressure and Borg 6-20 perceived exertion rating were continuously recorded throughout the test and standard criteria for test termination were used $(12,13)$. CRF [in Metabolic Equivalents (METs)] was calculated from peak treadmill speed and grade utilizing established metabolic equations from the American College of Sports Medicine (12). CRF was analyzed as a continuous as well as a categorical variable divided into 3 categories (Low CRF <5METs, Moderate CRF 5 to 10 METs and High CRF $>10$ METs) $(4,6)$.

Outcomes ascertainment. The Veterans Affairs CPRS was used for capturing cancer outcomes; total cancer mortality was the primary outcome. Previous reports have demonstrated that the Veterans Affairs death records are relatively complete compared to those from other sources, such as the Social Security Administration (14). The Veterans Affairs records have also good agreement (kappa= 0.82 to 0.91 ) with state death records (15). Medical records were carefully reviewed by qualified medical personnel who were otherwise blinded to treadmill test results and other study information. Cancer death was verified using International Classification of Diseases, ninth and tenth edition codes and the vital status for each patient was ascertained as of August 2015.

Statistical analysis. Demographic and clinical data of the participants are presented as mean \pm standard deviation. Categorical variables are presented in percentages. Comparisons between participants with low, moderate or high CRF were performed using analysis of variance for continuous variables and chi-square tests for categorical variables. Multivariable Cox proportional hazard models were used to assess the association between CRF and cancer mortality. The models were adjusted for age, body mass index, hypertension, hypercholesterolemia, diabetes, smoking status (never, former, current), smoking in pack-years and alcohol abuse (16-18). The hazard models also took into account competing events (death resulting from causes other than cancer) $(19,20)$. In order to address potential reverse causality bias, a secondary analysis was performed after excluding participants who had less than two years follow up. Population attributable fraction (PAF\%) for low CRF ( $<5$ METs) compared to $\geq 5$ METs as a risk factor was analyzed. PAF\% is a metric quantifying the contribution of a risk factor to the burden of disease or death and represents the proportional reduction in population disease or mortality burden that would occur if exposure to a risk factor was eliminated (e.g., no tobacco use). PAF\% was calculated using the equation $\mathrm{P}[$ Relative Risk(RR)-1]/[1+P(RR$1)]^{*} 100$ (21) where $P=$ prevalence of the risk factor and $R R=$ a fully adjusted relative risk calculated from the Cox hazard model accounting for competing events $(22,23)$. Kaplan-Meier curves using the log-rank test were constructed for CRF categories, with cancer mortality as the outcome. The proportional hazards assumption was evaluated graphically for CRF categories and confirmed using the scaled Schoenfeld residuals.

Exposure impact number (EIN) was calculated as EIN=1/[(RR$1) * \mathrm{PNE}]+\mathrm{RR} /[(\mathrm{RR}-1) *(1-\mathrm{PNE})]$ where $\mathrm{RR}=$ fully adjusted relative risk from Cox hazard model accounting for competing events and $\mathrm{PNE}=$ event rate in non-exposed population (24-27). EIN is the corresponding epidemiological measure of a number needed to treat (NNT), an analysis commonly used in randomized controlled trials. The EIN is the average number of exposed patients to the risk factor who would need to be removed from the exposure in order to prevent one additional adverse event or outcome. EIN and NNT permit quantification of effort needed to be taken for preventing one event, thus providing an objective comparison of cost-effectiveness with other treatments or interventions. In general, the lower EINs and NNTs suggest a more cost-effective intervention for the prevention of an adverse outcome (24-27). Data report and presentation followed the "Strengthening the Reporting of Observational Studies in Epidemiology" (STROBE) guidelines (28). SPSS (IBM, Chicago, IL, USA) version 23 was used for statistical analyses. The significance level was set at $\mathrm{p}<0.05$.

\section{Results}

The analytical sample included 342 male participants who developed digestive system cancers [colorectal $(n=224)$, gallbladder $(n=59)$, liver $(n=28)$, esophageal $(n=13)$, pancreatic $(n=13)$, intrahepatic bile duct $(n=3)$, stomach $(n=1)$ and anus $(n=1)$ ] during $6.7 \pm 5$ years from baseline assessment. Mean age was $68.9 \pm 21.8$ years, and mean CRF was $8.0 \pm 2.9$ METs. Demographic and clinical characteristics of the participants are presented in Table I. Approximately $27 \%$ were current smokers, $57 \%$ had hypertension, $41.5 \%$ had hypercholesterolemia, $33.3 \%$ were obese, $11.1 \%$ had a history of cardiovascular disease and $20.6 \%$ had diabetes at baseline. Participants with high CRF compared to participants with moderate and low CRF levels had lower pack/years of smoking, lower prevalence of hypertension and fewer fatalities related to cancer, and a higher prevalence of being physically active (Table I). 
Table I. Baseline demographic and clinical characteristics of the cohort.

\begin{tabular}{|c|c|c|c|c|c|}
\hline & Entire Cohort $(\mathrm{n}=342)$ & Low CRF ( $\mathrm{n}=53)$ & Moderate CRF $(n=210)$ & High CRF $(n=79)$ & $p$-Value \\
\hline Age (yr) & $68.9 \pm 21.8$ & $65.7 \pm 22.4$ & $68.9 \pm 22.1$ & $71.1 \pm 20.7$ & 0.371 \\
\hline BMI $\left(\mathrm{kg} / \mathrm{m}^{2}\right)$ & $28.8 \pm 5.3$ & $29.5 \pm 6.6$ & $29 \pm 5$ & $27.8 \pm 5.3$ & 0.128 \\
\hline Obesity $\left(\mathrm{BMI}>30 \mathrm{~kg} / \mathrm{m}^{2}\right)$ & $33.3 \%$ & $32.1 \%$ & $35.6 \%$ & $28.2 \%$ & 0.487 \\
\hline \multicolumn{6}{|l|}{ Smoking status } \\
\hline Never & $20.9 \%$ & $20 \%$ & $19.4 \%$ & $25.7 \%$ & \\
\hline Former & $52.3 \%$ & $46 \%$ & $54.7 \%$ & $50 \%$ & 0.571 \\
\hline Current & $26.8 \%$ & $34 \%$ & $25.9 \%$ & $24.3 \%$ & \\
\hline Smoking (pack/years) & $35.3 \pm 26.5$ & $52.4 \pm 34.6$ & $34.1 \pm 24$ & $26.1 \pm 25.4$ & $<0.001$ \\
\hline Hypertension & $57 \%$ & $71.7 \%$ & $56.2 \%$ & $49.4 \%$ & 0.037 \\
\hline Hypercholesterolemia & $41.5 \%$ & $32.1 \%$ & $41 \%$ & $49.4 \%$ & 0.137 \\
\hline Cardiovascular disease & $11.1 \%$ & $17 \%$ & $9.5 \%$ & $11.4 \%$ & 0.303 \\
\hline Diabetes & $20.6 \%$ & $22 \%$ & $21.9 \%$ & $16.3 \%$ & 0.848 \\
\hline Alcohol abuse & $4.1 \%$ & $3.8 \%$ & $4.3 \%$ & $3.8 \%$ & 0.975 \\
\hline Anti-hypertensive drugs & $14.6 \%$ & $35.8 \%$ & $11.4 \%$ & $8.9 \%$ & $<0.001$ \\
\hline Anti-hyperlipidemias & $12.6 \%$ & $9.4 \%$ & $13.3 \%$ & $12.7 \%$ & 0.746 \\
\hline CRF (METs) & $8 \pm 2.9$ & $4 \pm 0.7$ & $7.5 \pm 1.4$ & $11.9 \pm 1.8$ & $<0.001$ \\
\hline Physically active & $54.3 \%$ & $41.5 \%$ & $50 \%$ & $74.4 \%$ & $<0.001$ \\
\hline
\end{tabular}

Data presented as means \pm standard deviation or $\%$ of the group for categorical variables. BMI: Body mass index; CRF: cardiorespiratory fitness; METs: metabolic equivalents.

Table II. Hazard models and survival of cardiorespiratory fitness and cancer mortality in men who developed digestive system cancers.

\begin{tabular}{|c|c|c|c|c|c|c|}
\hline Group/CRF Categories & $\begin{array}{l}\text { Low CRF } \\
<5 \text { METs }\end{array}$ & $\begin{array}{l}\text { Moderate CRF } \\
5 \text { to } 10 \mathrm{METs}\end{array}$ & $\begin{array}{l}\text { High CRF } \\
>10 \text { METs }\end{array}$ & $p$-trend & 1-MET increase & $p$-Value \\
\hline Cancer mortality (n/\%) & $34(64.2 \%)$ & $70(33.3 \%)$ & $16(20.3 \%)$ & N/A & N/A & $<0.001$ \\
\hline Hazard ratios & 1 & 0.43 & 0.27 & 0.002 & 0.86 & 0.001 \\
\hline (95\% confidence interval) & (Reference) & $(0.24$ to 0.74$)$ & $(0.12$ to 0.59$)$ & & $(0.79$ to 0.94$)$ & \\
\hline $\begin{array}{l}\text { Mean survival time from baseline } \\
\text { (years and } 95 \% \text { confidence interval) }\end{array}$ & $\begin{array}{c}7.9 \\
(5.7 \text { to } 10.1)\end{array}$ & $\begin{array}{c}13.5 \\
(12.1 \text { to } 14.9)\end{array}$ & $\begin{array}{c}16.1 \\
(14.0 \text { to } 18.2)\end{array}$ & N/A & N/A & $<0.001$ \\
\hline
\end{tabular}

CRF: Cardiorespiratory fitness; MET: metabolic equivalent; N/A: not applicable. The risk models were adjusted for age, body mass index, hypertension, hypercholesterolemia, diabetes, smoking status (never, former, current) smoking in pack-years, alcohol abuse and accounted for competing events.

During a mean of $7.2 \pm 5$ years follow-up from baseline, 120 participants died from cancer and 3 participants died from causes other than cancer. In a continuous model, each 1-MET higher CRF was associated with a $14 \%$ reduced risk [0.86, 95\% CI $=0.79-0.94, p=0.001]$ for cancer mortality. In a categorical model where low CRF was used as the reference, moderate and high CRF levels were associated with $57 \%[0.43$, $95 \% \mathrm{CI}=0.24-0.74]$ and $73 \%[0.27,95 \% \mathrm{CI}=0.12-0.59]$ reduced risks for cancer mortality ( $p$ trend $=0.002$ ), respectively. Survival time from baseline was significantly longer among those with moderate [13.5 (range $=12.1-14.9$ ) years] and high [16.1 (range $=14.0-18.2$ ) years] compared to low CRF [7.9 (range=5.7-10.1) years], respectively (Table II and Figure 1). After exclusion of those with less than two years follow up, $\mathrm{CRF}$ remained a significant predictor of cancer mortality. The hazard ratios and $95 \%$ confidence intervals were 0.89 , $95 \% \mathrm{CI}=0.81-0.97, p=0.012$ in the continuous model and 0.51 , $95 \% \mathrm{CI}=0.27-0.99$ and $0.33,95 \% \mathrm{CI}=0.14-0.8$, $\mathrm{p}$ trend $=0.041$ in the categorical model for moderate and high CRF, respectively. PAF was 9.4\%, 95\% CI=5.2-12.0 and EIM was 4.5, $95 \% \mathrm{CI}=2.8-11.0, p=0.001$ (Table III).

\section{Discussion}

The current pilot study aimed to assess the association between pre-diagnosis CRF and cancer mortality in male participants who later developed digestive system cancers. The study also sought to quantify the potential public health implications of CRF in prevention and control of digestive system cancers. The findings demonstrated that 


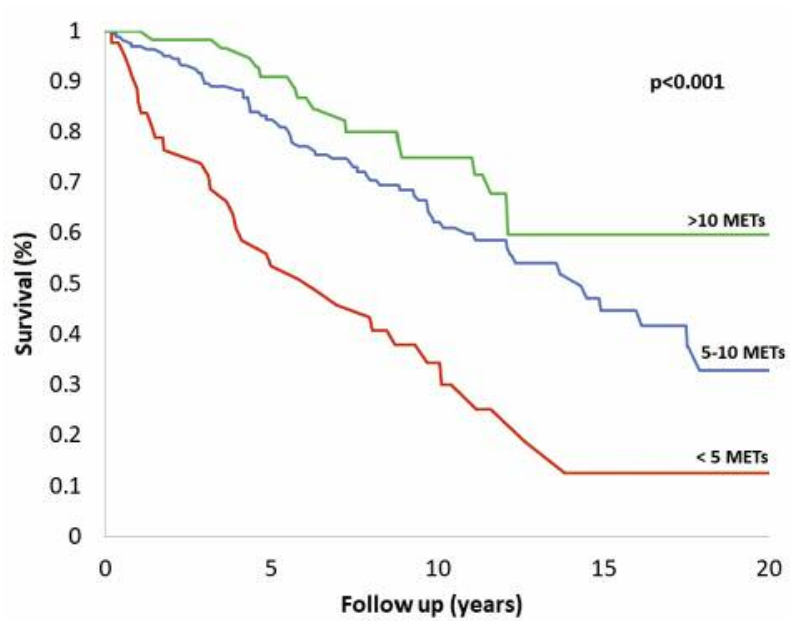

Figure 1. Kaplan-Meier survival curves of cardiorespiratory fitness categories and cancer mortality in men who developed digestive system cancers. MET: Metabolic equivalent.

higher pre-diagnosis CRF is independently associated with lower risk of cancer mortality and longer survival. For each one higher MET level, there was a 14\% reduced risk for cancer mortality (Table II). Eliminating low CRF as risk factor is potentially cost-effective which could potentially prevent $9.4 \%$ of cancer mortality in men who develop digestive system cancers later in life. While these observations do not indicate causality and require confirmation in larger prospective studies, they provide important information for cancer prevention and control. Since digestive system cancers are prevalent in the general population and are associated with poor survival particularly in men $(1,2)$, these findings have important public health implications for developing effective strategies for reducing mortality and improving survival in people who develop digestive system cancers. The data suggest that screening middle-age men for CRF and achieving higher fitness levels through regular exercise are potentially cost-effective strategies that could reduce mortality from cancer and improve survival time in men who later develop digestive system cancers.

The current results are consistent with previous studies on the relationship between CRF and incidence of colorectal and gastro-intestinal track cancers (6-8). The study also parallels a previous study on the inverse association between CRF and mortality from digestive system cancers in men from the general population (9). The present study extends this earlier report by providing novel data with respect to pre-diagnosis CRF and survival benefits in men who developed digestive system cancers. Particularly, the current study is the first to demonstrate a reduced risk of cancer mortality and longer survival time with higher prediagnosis CRF in men who develop digestive system cancers later in life. CRF remained a significant predictor of cancer mortality even after adjusting for potential confounders, accounting for competing events and excluding individuals with less than two years follow-up. In addition, the study provides novel data quantifying the potential public health implications of CRF in prevention and control of digestive system cancers. The PAF\% analysis showed that by eliminating low CRF as risk factor in the pre-diagnosis phase of digestive system cancers, $9.4 \%$ of cancer mortality could potentially be prevented in men who later develop digestive system cancers. The low EIN (approximately 5) supports that this strategy is potentially cost-effective. For every 5 men with low CRF ( $<5$ METs) that could be moved to $\geq 5$ METs, one cancer-related death could be avoided in men who develop digestive system cancers later in life (Table III). Given the extensive body of literature demonstrating that most people can improve $\geq 1$ MET with a regular exercise program (4), screening for impaired CRF and achieving higher levels can potentially improve survival from cancer in men who develop digestive system cancers. However, larger prospective studies are needed to confirm this observation.

Although the precise mechanisms by which higher prediagnosis CRF might provide protective benefits are not fully understood, there are several potential explanations. Digestive system cancers such as colorectal, stomach and pancreatic are associated with obesity, physical inactivity, smoking and heavy alcohol consumption $(1,16)$. These are related to increased systemic inflammation, abnormal metabolic and hormonal states, compromised immune function and oxidative stress (29-33). In contrast, higher CRF is associated with lower chronic inflammation, enhanced immune system function, reduced oxidative stress and elevated antioxidant capacity, as well as enhanced hormonal and metabolic regulation $(4,34)$. Additionally, higher CRF is a well-established health marker associated with reduced risk of all-cause, cardiovascular and cancerrelated mortality in the general population as well as those with chronic conditions $(4,5)$. It is possible that higher prediagnosis CRF conferred some protection with respect to cancer progression, metastasis and ultimately cancer death (31-33). However, despite growing observational evidence supporting the concept that CRF has a role in reduced risk of cancer mortality $(4,5,9)$, prospective and mechanistic studies are warranted.

The strengths of the current study include a prospective assessment of cancer mortality outcomes and extended follow-up time (mean of approximately 7 years). In addition, outcomes were verified through the Veterans Affairs computerized medical records system, which has been demonstrated to be comparatively accurate and complete (14, 
Vainshelboim et al: CRF and Digestive System Cancers

Table III. Population attributable fraction and exposure impact number of low cardiorespiratory fitness in men who developed digestive system cancers.

\begin{tabular}{lcccc}
\hline Prevalence of low CRF (<5 METs) & Relative risks (95\%CI) & PAFs\% (95\%CI) & EIN (95\%CI) & $p$-Value \\
\hline $15.5 \%$ & $2.5(1.5-4.4)$ & $9.4(6.4-12.2)$ & $4.5(2.8-11.0)$ & $<0.001$ \\
\hline
\end{tabular}

CI: Confidence interval; CRF: cardiorespiratory fitness; EIN: exposure impact number; MET: metabolic equivalent; PAF: population attributable fraction. The risk models were adjusted for age, body mass index, hypertension, hypercholesterolemia, diabetes, smoking status (never, former, current) smoking in pack-years, alcohol abuse and accounted for competing events.

35, 36). CRF was quantified from treadmill exercise testing utilizing established protocols $(12,13)$. This method has been widely used in epidemiological studies and has been shown to be strongly predictive for total cancer mortality and mortality from digestive system cancers $(4-6,8,9)$. The study also has several limitations. First, although the sample size was relatively small and individuals with different digestive system cancers were included, the number of deaths enabled fully adjusted multivariable analyses, providing an independent association between CRF and cancer death. Second, although the multivariable hazard models were adjusted for established confounders similar to those in previous studies $(6,9)$, data on dietary habits were not available, which may have an influence on risk. Third, Veteran participants are a unique population with a rich mixture of co-morbidities that may have influenced the results by selection bias, although the findings are consistent with previous reports of CRF and digestive system cancer outcomes $(6,8,9)$. Fourth, the study was limited to men, and the extent to which the findings apply to women requires further investigation. Finally, as is the case in all epidemiological studies, the findings provide an association between exposure (CRF) and adverse outcome (cancer mortality), but preclude the establishment of cause and effect.

In summary, higher pre-diagnosis CRF is independently associated with a lower risk of cancer mortality and longer survival time in men who later developed digestive system cancers. Eliminating low CRF as risk factor could reduce mortality from cancer and extends survival. In addition to established screening tools for colorectal cancer, assessing and encouraging improvements in CRF may serve as a costeffective public-health strategy for the prevention and control of digestive system cancers. Future large prospective studies should be conducted to ascertain these findings and further explore the impact of promoting CRF in primary and secondary prevention in this population.

\section{Conflicts of Interest}

The Authors declare there are no conflicts of interest regarding this study.

\section{Authors' Contributions}

BV was responsible for study design and conception, statistical analysis, results interpretation, drafting, writing and submitting the manuscript. ZC contributed to the conception and design of the study, was responsible for data collection, contributed to results interpretation, drafting the article and revising it critically for important intellectual content. JM contributed to the conception and design of the study, served as principle investigator of the study, data collection and results interpretation, contributed to drafting the article and revising it critically for important intellectual content. All Authors read and approved the final version.

\section{References}

1 Cancer facts \& figures 2019. Atlanta: American cancer society (2019). Available at https://www.cancer.org/content/dam/cancer$\mathrm{org} /$ research/cancer-facts-and-statistics/annual-cancer-facts-andfigures/2018/cancer-facts-and-figures-2018.pdf.

2 Bray F, Ferlay J, Soerjomataram I, Siegel RL, Torre LA and Jemal A: Global cancer statistics 2018: Globocan estimates of incidence and mortality worldwide for 36 cancers in 185 countries. CA Cancer J Clin, 2018. PMID: 30207593. DOI: 10.3322/caac.21492

3 Smith RA, Andrews KS, Brooks D, Fedewa SA, ManassaramBaptiste D, Saslow D, Brawley OW and Wender RC: Cancer screening in the United States, 2018: A review of current american cancer society guidelines and current issues in cancer screening. CA Cancer J Clin 68(4): 297-316, 2018. PMID: 29846940. DOI: $10.3322 /$ caac. 21446

4 Ross R, Blair SN, Arena R, Church TS, Despres JP, Franklin BA, Haskell WL, Kaminsky LA, Levine BD, Lavie CJ, Myers J, Niebauer J, Sallis R, Sawada SS, Sui X, Wisloff U, American Heart Association Physical Activity Committee of the Council on L, Cardiometabolic H, Council on Clinical C, Council on E, Prevention, Council on C, Stroke N, Council on Functional G, Translational B and Stroke C: Importance of assessing cardiorespiratory fitness in clinical practice: A case for fitness as a clinical vital sign: A scientific statement from the american heart association. Circulation 134(24): e653-e699, 2016. PMID: 27881567. DOI: $10.1161 /$ CIR.0000000000000461

5 Schmid D and Leitzmann MF: Cardiorespiratory fitness as predictor of cancer mortality: A systematic review and metaanalysis. Ann Oncol 26(2): 272-278, 2015. PMID: 25009011. DOI: $10.1093 /$ annonc/mdu250

6 Lakoski SG, Willis BL, Barlow CE, Leonard D, Gao A, Radford NB, Farrell SW, Douglas PS, Berry JD, DeFina LF and Jones 
LW: Midlife cardiorespiratory fitness, incident cancer, and survival after cancer in men: The cooper center longitudinal study. JAMA Oncol 1(2): 231-237, 2015. PMID: 26181028. DOI: $10.1001 /$ jamaoncol.2015.0226

7 Marshall CH, Al-Mallah MH, Dardari Z, Brawner CA, Lamerato LE, Keteyian SJ, Ehrman JK, Visvanathan K and Blaha MJ: Cardiorespiratory fitness and incident lung and colorectal cancer in men and women: Results from the henry ford exercise testing (fit) cohort. Cancer, 2019. PMID: 31056756. DOI: 10.1002/cncr. 32085

8 Laukkanen JA, Pukkala E, Rauramaa R, Makikallio TH, Toriola AT and Kurl S: Cardiorespiratory fitness, lifestyle factors and cancer risk and mortality in finnish men. Eur J Cancer 46(2): 355363, 2010. PMID: 19683431. DOI: 10.1016/j.ejca. 2009.07. 013

9 Peel JB, Sui X, Matthews CE, Adams SA, Hebert JR, Hardin JW, Church TS and Blair SN: Cardiorespiratory fitness and digestive cancer mortality: Findings from the aerobics center longitudinal study. Cancer Epidemiol Biomarkers Prev 18(4): 1111-1117, 2009. PMID: 19293313. DOI: 10.1158/10559965.EPI-08-0846

10 Myers J, Nead KT, Chang P, Abella J, Kokkinos P and Leeper NJ: Improved reclassification of mortality risk by assessment of physical activity in patients referred for exercise testing. Am J Med 128(4): 396-402, 2015. PMID: 25511076. DOI: 10.1016/ j.amjmed.2014.10.061

11 Myers J, Prakash M, Froelicher V, Do D, Partington S and Atwood JE: Exercise capacity and mortality among men referred for exercise testing. N Engl J Med 346(11): 793-801, 2002. PMID: 11893790. DOI: 10.1056/NEJMoa011858

12 American College of Sports Medicine: Acsm's guidelines for exercise testing and prescription. 9th edn. Wolters Kluwer/ Lippincott Williams \& Wilkins Health: Philadelphia, 2014.

13 Fletcher GF, Ades PA, Kligfield P, Arena R, Balady GJ, Bittner VA, Coke LA, Fleg JL, Forman DE, Gerber TC, Gulati M, Madan K, Rhodes J, Thompson PD, Williams MA, American Heart Association Exercise CR, Prevention Committee of the Council on Clinical Cardiology CoNPA, Metabolism CoC, Stroke N, Council on E and Prevention: Exercise standards for testing and training: A scientific statement from the american heart association. Circulation 128(8): 873-934, 2013. PMID: 23877260. DOI: 10.1161/CIR.0b013e31829b5b44

14 Page WF, Mahan CM and Kang HK: Vital status ascertainment through the files of the department of veterans affairs and the social security administration. Ann Epidemiol 6(2): 102-109, 1996. PMID: 10068251.

15 Dominitz JA, Maynard C and Boyko EJ: Assessment of vital status in department of veterans affairs national databases. Comparison with state death certificates. Ann Epidemiol 11(5): 286-291, 2001. PMID: 11399441.

16 Food, nutrition, physical activity, and the prevention of cancer: A global perspective. (2007). Available at http://www.aicr.org/ assets/docs/pdf/reports/Second_Expert_Report.pdf

17 Schuz J, Espina C, Villain P, Herrero R, Leon ME, Minozzi S, Romieu I, Segnan N, Wardle J, Wiseman M, Belardelli F, Bettcher D, Cavalli F, Galea G, Lenoir G, Martin-Moreno JM, Nicula FA, Olsen JH, Patnick J, Primic-Zakelj M, Puska P, van Leeuwen FE, Wiestler O, Zatonski W and Working Groups of Scientific E: European code against cancer 4th edition: 12 ways to reduce your cancer risk. Cancer Epidemiol 39: S1-10, 2015. PMID: 26164654. DOI: 10.1016/j.canep.2015.05.009
18 Islami F, Goding Sauer A, Miller KD, Siegel RL, Fedewa SA, Jacobs EJ, McCullough ML, Patel AV, Ma J, Soerjomataram I, Flanders WD, Brawley OW, Gapstur SM and Jemal A: Proportion and number of cancer cases and deaths attributable to potentially modifiable risk factors in the united states. CA Cancer J Clin 68(1): 31-54, 2017. PMID: 29160902. DOI: 10.3322/caac. 21440

19 Satagopan JM, Ben-Porat L, Berwick M, Robson M, Kutler D and Auerbach AD: A note on competing risks in survival data analysis. Br J Cancer 91(7): 1229-1235, 2004. PMID: 15305188. DOI: $10.1038 /$ sj.bjc.6602102

20 Fine JP and Gray RJ: A proportional hazards model for the subdistribution of a competing risk. J Am Stat Assoc 94(446): 496-509, 1999. DOI: $10.2307 / 2670170$

21 Northridge ME: Public health methods--attributable risk as a link between causality and public health action. Am J Public Health 85(9): 1202-1204, 1995. PMID: 7661224. DOI: 10.2105/ajph.85. 9.1202

22 Song M and Giovannucci E: Preventable incidence and mortality of carcinoma associated with lifestyle factors among white adults in the united states. JAMA Oncol 2(9): 1154-1161, 2016. PMID: 27196525. DOI: 10.1001/jamaoncol.2016.0843

23 Greenland S: Interval estimation by simulation as an alternative to and extension of confidence intervals. Int J Epidemiol 33(6): 1389-1397, 2004. PMID: 15319402. DOI: 10.1093/ije/dyh276

24 Cook RJ and Sackett DL: The number needed to treat: A clinically useful measure of treatment effect. BMJ 310(6977): 452-454, 1995. PMID: 7873954. DOI: $10.1136 / \mathrm{bmj} .310$. 6977.452

25 Bender R and Blettner M: Calculating the "number needed to be exposed" with adjustment for confounding variables in epidemiological studies. J Clin Epidemiol 55(5): 525-530, 2002. PMID: 12007557. DOI: 10.1016/s0895-4356(01)00510-8

26 Bender R, Kuss O, Hildebrandt M and Gehrmann U: Estimating adjusted nnt measures in logistic regression analysis. Stat Med 26(30): 5586-5595, 2007. PMID: 17879268. DOI: 10.1002/ sim.3061

27 Mendes D, Alves C and Batel-Marques F: Number needed to treat (nnt) in clinical literature: An appraisal. BMC Med 15(1): 112, 2017. PMID: 28571585. DOI: 10.1186/s12916-017-0875-8

28 Vandenbroucke JP, von Elm E, Altman DG, Gotzsche PC, Mulrow CD, Pocock SJ, Poole C, Schlesselman JJ and Egger M; STROBE initiative: Strengthening the reporting of observational studies in epidemiology (strobe): Explanation and elaboration. Ann Intern Med 147(8): W163-194, 2007. PMID: 17938389. DOI: 10.7326/0003-4819-147-8-20071016000010-w1

29 Katzke VA, Kaaks R and Kuhn T: Lifestyle and cancer risk. Cancer J 21(2): 104-110, 2015. PMID: 25815850. DOI: 10.1097/PPO.0000000000000101

30 Ligibel J: Lifestyle factors in cancer survivorship. J Clin Oncol 30(30): 3697-3704, 2012. PMID: 23008316. DOI: 10.1200/ JCO.2012.42.0638

31 Westerlind KC: Physical activity and cancer prevention-mechanisms. Med Sci Sports Exerc 35(11): 1834-1840, 2003. PMID: 14600547. DOI: 10.1249/01.MSS.0000093619.37805.B7

32 Hojman P, Gehl J, Christensen JF and Pedersen BK: Molecular mechanisms linking exercise to cancer prevention and treatment. Cell Metab 27(1): 10-21, 2018. PMID: 29056514. DOI: 10.1016/j.cmet.2017.09.015 
33 Rogers CJ, Colbert LH, Greiner JW, Perkins SN and Hursting SD: Physical activity and cancer prevention: Pathways and targets for intervention. Sports Med 38(4): 271-296, 2008. PMID: 18348589. DOI: 10.2165/00007256-200838040-00002

34 Farrell PA, Joyner MJ and Caiozzo VJ: Acsm's advanced exercise physiology: Second edition. Lippncott Williams \& Wilkins: Baltimore, 2012.

35 Floyd JS, Blondon M, Moore KP, Boyko EJ and Smith NL: Validation of methods for assessing cardiovascular disease using electronic health data in a cohort of veterans with diabetes. Pharmacoepidemiol Drug Saf 25(4): 467-471, 2016. PMID: 26555025. DOI: $10.1002 /$ pds.3921
36 McCarron KK, Reinhard MJ, Bloeser KJ, Mahan CM and Kang HK: Ptsd diagnoses among iraq and afghanistan veterans: Comparison of administrative data to chart review. J Trauma Stress 27(5): 626-629, 2014. PMID: 25322891. DOI: 10.1002/ jts. 21961
Received August 22, 2019

Revised September 3, 2019

Accepted September 4, 2019 